\title{
Metodología de Aprendizaje Basada en Metáforas Narrativas y Gamificación: Un caso de estudio en un Programa de Posgrado Semipresencial
}

\section{Learning Methodology Based on Narrative Metaphors and Gamification: A case study in a blended Master's Program}

\author{
Janio Jadán-Guerrero ${ }^{1}$ \\ Carlos Ramos-Galarza ${ }^{2}$ \\ Universidad Tecnológica Indoamérica, Ecuador \\ Pontificia Universidad Católica del Ecuador
}

Recibido: 15-01-2018

Aceptado: 18-06-2018

\section{Cita Recomendada}

Jadán-Guerrero, J. \& Ramos-Galarza, C. (2018) Metodología de Aprendizaje Basada en Metáforas Narrativas y Gamificación: Un caso de estudio en un Programa de Posgrado Semipresencial. Hamut'ay, 5 (1), 84-104. http://dx.doi.org/10.21503/hamu.v5i1.1560

\section{RESUMEN}

Este artículo describe una experiencia de innovación en el aula universitaria mediante una metodología basada en metáforas narrativas y estrategias de gamificación para la enseñanza de la tecnología. El objetivo de esta metodología fue la aplicación de estrategias didácticas para generar interacción y motivación en jornadas extensas de clase. Para ello se presenta un caso de estudio en el que participaron 62 estudiantes del programa de Maestría en Educación, Innovación y Liderazgo Educativo de la ciudad de Ambato, en Ecuador. En el estudio se utilizó la plataforma de aprendizaje Moodle y un conjunto de herramientas de la web 2.0. La recolección de información se realizó principalmente en foros mediante las narraciones realizadas por los estudiantes y una encuesta para medir el grado de motivación. A través de estos instrumentos se identificaron los principales resultados de la evaluación de la experiencia. Entre los más relevantes, cabe destacar un aumento del porcentaje en el cual, la innovación de los procesos de enseñanza-aprendizaje en el aula fomentan interacción, motivación e involucramiento, características que inciden en el aprendizaje significativo..

Palabras Clave: Gamificación, metáforas, tecnología, TIC, posgrados, semipresencial.

\footnotetext{
1 Doctor en Ciencias de la Computación de la Universidad de Costa Rica y actualmente es el Director de Investigación de la Universidad Tecnológica Indoamérica en Ecuador y del Centro de Investigación en Mecatrónica y Sistemas Interactivos-MIST. Su línea de investigación es la de Interacción Humano-Computador y Tecnologías para la Educación Especial, janiojadan@uti.edu.ec 2 Doctor en Psicología de la Universidad de Concepción de Chile y actualmente catedrático de la Facultad de Psicología de la Pontificia Universidad Católica del Ecuador e Investigador del Centro de Investigación en Mecatrónica y Sistemas Interactivos-MIST, su línea de investigación es neurociencias, caramos@puce.edu.ec
} 


\begin{abstract}
This article describes an innovation experience in the university classroom through a methodology based on narrative metaphors and gamification strategies for teaching technology. The objective of this methodology was the application of didactic strategies to generate interaction and motivation in extended day classes. To this end, a case study was presented in which 62 students participated in the Master's program in Education, Innovation and Educational Leadership of the city of Ambato, in Ecuador. The Moodle learning platform and a set of webs 2.0 tools were used in the study. The information was collected mainly in forums through the narrations made by the students and a survey to measure the degree of motivation. Through these instruments, the main results of the evaluation of the experience were identified. Among the most relevant, it is worth noting an increase in the percentage in which, the innovation of the teaching-learning processes in the classroom fosters interaction, motivation and involvement, characteristics that impact on significant learning.
\end{abstract}

Keywords: Gamification, metaphors, technology, ICT, master's programs, blended..

\section{INTRODUCCIÓN}

En la actualidad existen programas de maestría adaptados a ciertos horarios, que facilitan a estudiantes y profesionales a trabajar y estudiar al mismo tiempo. Este tipo de programas utilizan la modalidad semipresencial, en los cuales se cubren cuarenta horas académicas en cinco sesiones. En el Ecuador existen maestrías con esta modalidad en diferentes áreas del conocimiento, que si bien esto constituye un aporte para aquellos profesionales que desean seguir formándose y ser competitivos en su área profesional; esto se ve mermado por las extensas y extenuantes jornadas de un módulo que consiste en ocho horas continuas.

En este contexto la introducción de la tecnología juega un papel importante, de forma particular las plataformas virtuales de aprendizaje, que ayudan a complementar actividades de aprendizaje mediante trabajo autónomo de los estudiantes. $\mathrm{Si}$ bien, estas herramientas abren las posibilidades de una revolución educativa, aún no se aprovecha la capacidad que ellas brindan. Las formas de enseñanza no han mutado y siguen una corriente tradicionalista, ya que se continúa impartiendo clases magistrales, en las que el docente solo habla y los estudiantes tienen que quedarse callados escuchando. En el mejor de los casos se introduce la tecnología en el aula mediante un computa- dor y un proyector que apoyan al docente con la proyección de diapositivas. Aun así, el proceso se torna monótono, si el docente no usa estrategias didácticas para hacer la clase más dinámica. Por otro lado, no todos los docentes usan las plataformas educativas, en ciertos casos son utilizadas como simples repositorios de archivos.

En conclusión, las instituciones educativas actualmente no aplican una metodología que permita aprender de forma didáctica y creativa. Los estudiantes se desmotivan a la hora de aprender, conllevando además a ser un problema que el docente debe afrontar para evitar que el estudiante se aburra. Lo cual constituye un desafío para el docente lograr que los estudiantes se involucren en el desarrollo de las asignaciones que deben hacerlas dentro y fuera del aula, retos que deben ser asumidos y buscar nuevas estrategias para lograr una formación de calidad en los estudiantes del nivel de posgrado. Por lo tanto, se hace necesaria la implementación de estrategias metodológicas alternativas para llevar a cabo el proceso de enseñanza-aprendizaje; una de ellas y de especial interés de este estudio es la gamificación, la cual combina tecnología, juego educativo y estrategia de refuerzo positivo (Torres \& Lázaro, 2016; Torres-Toukoumidis, Romero-Rodríguez \& Pérez-Rodríguez, 2018). Ante estos desafíos surge la 
Metodología de Aprendizaje Basada en Metáforas Narrativas y Gamificación: Un caso de estudio en un Programa de Posgrado Semipresencial

pregunta de investigación ¿Es posible incorporar metáforas narrativas y elementos de gamificación en una plataforma virtual de aprendizaje para fortalecer la interacción y motivación de estudiantes de posgrado?

Para responder a esta pregunta se presenta un caso de estudio en el que se aplica una metodología basada en metáforas narrativas y estrategias de gamificación, con el fin de hacer más entretenidas las largas jornadas, tanto presenciales como virtuales en el contexto universitario. Con base en investigaciones realizadas en otros países se han encontrado que han dado buenos resultados en programas de pregrado (Pastor-Pina, Satorre-Cuerda, Molina-Carmona, Gallego-Durán, \& Llorens-Largo, 2015; Oliva, 2016; Llorens-Largo, Gallego-Durán, Villagrá-Arnedo, Compañ-Rosique, Satorre-Cuerda, \& Molina-Carmona, 2016; Llorens-Largo, 2017). Sin embargo, en el contexto latinoamericano existen pocas evidencias en programas de posgrado (Avello, Rodríguez $\&$ Dueñas., 2016) y de tipo semipresencial (Área, San Nicolás \& Fariña, 2010).

El objetivo general del estudio es la implementación de estrategias lúdicas y la aplicación de metáforas como elementos activos de la formación de estudiantes adultos, pertenecientes al programa de posgrado en Educación, Innovación y Liderazgo Educativo de la modalidad semipresencial. Para llevar a cabo este estudio, se plantearon tres objetivos específicos: El primero, introducir las Tecnologías de Información y la Comunicación (TIC) en la enseñanza, a través de recursos tecnológicos físicos y digitales mediados por una plataforma virtual de aprendizaje. Los recursos son organizados en aulas metafóricas, en las cuales se analizan situaciones reales o ficticias, que ayudan a entender y aplicar el contenido del módulo en actividades prácticas. La modalidad de estudio es de tipo b-learning (por sus siglas en inglés: Blended Learning), es decir un tipo de educación mixta en donde se combinan actividades en la clase y actividades virtuales para el tiempo de trabajo autónomo del estudiante.

El segundo objetivo, consistió en aplicar el uso de metáforas narrativas, las cuales han resultado útiles para el éxito de los estudiantes, especialmente cuando tienen que asumir nuevos conceptos y abstracciones, vitales para adquirir las competencias que recogen sus respectivos planes de estudio (Camacho \& Fuentes, 2013; Duran, 2015; Álvarez, Belmonte \& Román, 2016).

El tercer objetivo consistió en aplicar estrategias de gamificación, es decir la inclusión de elementos de los juegos en contextos que no son juegos como los procesos de enseñanza-aprendizaje, que, según estudios recientes, constituyen un tópico prometedor en el ámbito de la educación debido a las posibilidades de interacción y motivación que pueden generar en los estudiantes (Morales, 2013; Willging, Astudillo, Bast, Castro, \& Distel, 2014; Martí-Parreño, Queiro-Ameijeiras, Méndez-Ibáńez, \& Giménez-Fita, 2015; Minović, García-Peñalvo, \& Kearney, 2016; Lojan, 2017).

A continuación, se describen estudios relacionados con los tres objetivos que contempla el presente artículo, que se resumen en: la introducción de la tecnología en el aula, el uso de metáforas narrativas y el diseño de estrategias de gamificación.

\section{Las Tecnologías de la Información y Comunica-} ción (TIC) en la enseñanza

Las TIC han permitido que la modalidad de la educación cambie, hoy en día las clases ya no sólo son en las aulas, los Entornos Virtuales de Aprendizaje (EVA) o Plataformas Virtuales impulsan a que se pueda estudiar desde casa, además que permiten reforzar y reorientar las acciones formativas con un amplio contexto de recursos para las distintas fases del proceso formativo (Duran, 2015). Pues, estas herramientas tecnológicas en el campo de la educación abren nuevas formas, estrategias y métodos en los procesos de enseñanza-aprendizaje. Cada vez se aplican no sólo en sistemas de educación primaria y secundaria, también se están aplicando en ambientes universitarios, especialmente las plataformas virtuales (Área, San Nicolás \& Fariña, 2010).

Sin embargo, aún se siguen utilizando como simples repositiorios de documentos y eso ha dado lugar a estudios en donde se incorporan herramientas de la web 2.0 (Avello, Rodríguez \& Dueñas, 2016). Tradicionalmente el e-learning se 
ha vinculado con la educación a distancia (Área, San Nicolás \& Fariña, 2010). Evidentemente, las aulas virtuales de e-learning son poderosas herramientas que han permitido incrementar la calidad de los procesos formativos a distancia, y los estudios ofertados por este tipo de instituciones educativas han sido pioneros en el desarrollo de aulas virtuales en la docencia universitaria desarrolladas bajo la modalidad de blended learning o enseñanza semipresencial (Garibay \& Angelone, 2010).

En este contexto, una de las plataformas tecnológicas que ha tenido notoriedad es Moodle (Modular Object-Oriented Dynamic Learning Environment) (Morgado \& Schmidt, 2012), la cual fue diseñada para crear ambientes de aprendizaje personalizados (Avello, Rodríguez \& Dueñas, 2016).

Navarro (2010) indica acertadamente que no necesariamente la tecnología de punta favorecerá a la educación, sino que la verdadera evolución se localiza en las formas de concebir, planear, implementar y evaluar las acciones educativas dotadas de tecnología, que están bajo la condición de usarse para cumplir la finalidad de educar. Por ello, la tecnología se considera como una herramienta didáctica siempre y cuando su implementación persiga un objetivo educativo. La tecnología es la que involucra a los docentes y estudiantes en la construcción de sus propios conocimientos mediante la utilización de estrategias innovadoras, en la cual vaya generando nuevos cambios de aprendizaje mediante la utilización de recursos tecnológicos para el beneficio de la enseńanza aprendizaje de los estudiantes a futuro. La tecnología ayuda al estudiante a intercambiar conocimientos, de una manera más eficiente y fácil siendo su aprendizaje duradero que se aplicará en la formación de su vida profesional (Cruz, Rivadeneira, Villanova, Torres \& Varas, 2015; Rama, 2014).

A nivel universitario las TIC han dado lugar a nuevas estrategias de aprendizaje (Guarneros-Reyes, Espinoza-Zepeda, Silva, \& Sánchez-Sordo, 2016) y no sólo con el uso de plataformas virtuales de aprendizaje, sino también con el uso de tecnología de punta, como el uso de pizarras, in- teractivas, dispositivos móviles, entre ellos, tabletas y teléfonos inteligentes; así como educación ubicua mediante el uso de sensores (Guerrero, Peña, D., Peña, A. \& Serna, 2017).

\section{Aplicación de las Metáforas Narrativas}

Las metáforas han desempeñado un papel muy importante en las ciencias ya que se han convertido en instrumentos pedagógicos para la transmisión del conocimiento. Por ejemplo, en la Psicología, Platón comparaba la impresión de una «memoria» en la «mente» con la impresión que hacía un sello o un estilo sobre una tablilla de cera (Lazarte, 1995). En Computación, las metáforas son muy conocidas (Alarcón, Díaz, Tagle, Ramos, \& Quintana, 2014), ya que estas permiten comunicar conceptos abstractos de una manera accesible y familiar, por ejemplo, la metáfora del escritorio, que representa una interfaz en donde el usuario coloca documentos y carpetas de uso frecuente (Bermúdez, 2007). En las Matemáticas, se usan las metáforas para la representación y comprensión de conceptos abstractos, los paréntesis, pueden ser representados como metáforas, en el sentido de que encierran explícitamente un determinado contenido. Con la introducción de las TIC en el aula, las metáforas son aún más comunes, en especial en asignaturas como la Física y las Matemáticas que ayudan a interiorizar los conceptos abstractos en niños (Alvites-Huamaní, 2017).

Las metáforas están representadas por un ícono que permite la decodificación rápida, de un golpe de vista: la papelera, el sobre de carta tradicional para representar los mensajes de correo electrónico, la lupa para las búsquedas, la tijera para cortar, etc. También hay metáforas auditivas, como el sonido del crujido de un papel arrugado cuando mandamos un documento a la papelera. Gracias a este recurso retórico, el usuario puede comprender fácilmente eso que necesita utilizar en su dispositivo, de un programa o quiera realizar una operación para modificar el texto que produce, $y$ se ahorra, de este modo, una serie de aprendizajes referidos al sistema operativo que resultaría complejos para las personas no especializadas. En muchos casos, tampoco importa la lengua que hable 
Metodología de Aprendizaje Basada en Metáforas Narrativas y Gamificación: Un caso de estudio en un Programa de Posgrado Semipresencial

el usuario, ya que los íconos visuales y auditivos resultan universales.

Esta accesibilidad, paralela al desarrollo de internet, contribuyó enormemente ampliar la base de usuarios, lo cual tuvo un profundo impacto comercial, social y comunicativo (Alarcón, Díaz, Tagle, Ramos, \& Quintana, 2014; Duran, 2015). Asimismo, en el estudio de Capted (2011) "Metáforas visuales en los mundos virtuales. El caso de NANEC 2010/11", aborda el apoyo que las metáforas brindan en la narrativa visual, en este sentido los mundos virtuales representan un ambiente que permite la generación del aprendizaje, el estudio aporta con las directrices teóricas necesarias en los aspectos de identidad como parte del trabajo colaborativo y el trabajo en equipo.

El contexto es la fase más importante ya que la metáfora sugiere el uso de avatares, que permiten vivir una realidad paralela para generar el aprendizaje, la inmersión traspasando los límites de la ficción ya que el participante forma parte de la historia, comunicación que plantea al usuario procesar la información de la vida real con lo que se presenta en la Web (Capted, 2011). De acuerdo a Rojas, (2012) en su investigación sobre el uso de metáforas narrativas como hilo conductor en el diseńo de aulas virtuales, explica que proporcionan congruencia a las ideas, procedimientos y actitudes involucrados, y a disminuir la brecha entre lo que se quiere hacer y lo que realmente se hace, determina que el aula metafórica debe direccionarse a la integración de los conocimientos, a través de una historia y un hilo conductor que le permite al participante sentirse parte del entorno, siendo el profesor uno de los transmisores de los conocimientos de los estudiantes en el proceso enseñanza-aprendizaje.

El docente desempeña un papel importante al momento de impartir el aprendizaje a los estudiantes, de igual manera interactuando con sus pares, proporcionando buenos resultados académicos, ya que llegan a tener confianza y preguntan los espacios vacíos que tiene en el momento de la enseñanza-aprendizaje.

En el ámbito de la educación virtual, con la aparición de las plataformas, Camacho \& Fuentes (2013) han acuñado el término Aulas Metafóricas $\mathrm{y}$ consideran que es un espacio para que cualquier persona genere conocimientos a través del aprendizaje social, ya que existe interacción entre los participantes, se aplican recursos y metodologías que aportan al aspecto socio educativo (Camacho $\&$ Fuentes, 2013). Duran, (2015) expresa que son "aulas de gran complejidad tanto en su contextualización como en su diseño. Son concebidas sobre la base de metáforas gráficas y contenidos multimediales interactivos, que sumergen al participante en el contexto basado en una historia que combina la realidad con la ficción y donde el participante asume un rol protagónico y colaborativo".

\section{Diseño de estrategias de Gamificación}

El juego tiene un papel importante en la vida de los niños y niñas, es algo que nadie pone en duda. El ser humano se pasa la vida jugando, y en muchas ocasiones no solo es entretenimiento, sino que se puede convertir en terapia y en una manera distinta de aprender.

En los últimos años, se oye hablar mucho, en ambientes educativos, de la "gamificación" o lo que es lo mismo "introducir el juego en las aulas para mejorar el rendimiento, la concentración, el esfuerzo, y otros valores que motiven a los estudiantes (Rodríguez, 2015; Torres, 2016; Torres-Toukoumidis, Romero-Rodríguez \& Pérez-Rodríguez, 2018).

Siendo más específicos el término "gamificación" es un anglicismo ampliamente utilizado que proviene de la palabra gamification. El término se originó en la industria de los medios digitales en el año 2008, pero fue ampliamente adoptado después de la segunda mitad del 2010.

La gamificación se define como el uso de elementos de juegos. La definición de gamificación excluye explícitamente a los juegos serios, la cual es otra tecnología emergente que también hace uso del juego, pero con un propósito principal distinto del de la pura diversión. La principal diferencia entre la gamificación y juegos serios consiste en que los juegos serios son juegos completos, mientras que la gamificación es una manera de diseñar aplicaciones y servicios utilizando elementos de juegos (Vargas-Enríquez, García-Mundo, Gene- 
ro, \& Piattini, 2015).

Asimismo, Rodríguez \& Santiago en su libro "Gamificación: Cómo motivar a tu alumnado y mejorar el clima en el aula" define la gamificación cómo la realización de actividades con el juego para conseguir un propósito, haciendo que estas actividades sean divertidas aumentando la fortaleza moral con cada pequeńa victoria y con cada nuevo aprendizaje (Rodríguez \& Santiago, 2015).

Por su parte, Díaz \& Troyano (2013) en su artículo "El Potencial de la Gamificación aplicado al ámbito educativo" aclaran mucho sobre el tema. Dichos autores ponen en antecedentes y señalan que son Gabe Zichermann y Christopher Cunningham los que comienzan a hablar de gamificación en su obra "Gamification by Design" definiéndola como un proceso relacionado con el pensamiento del jugador y las técnicas de juego para atraer a los usuarios y resolver problemas. La gamificación de aplicaciones es actualmente muy popular, usándose por lo general para atraer a las nuevas generaciones, que necesitan una motivación constante.

Por otra parte, en el ámbito educativo los educadores continuamente están buscando formas de innovar el proceso de enseñanza-aprendizaje a fin de disminuir la deserción escolar y en general hacer este proceso más efectivo en términos de una mejor comprensión de los contenidos de las asignaturas y en consecuencia un incremento de los índices de aprobación (Rodríguez \& Santiago, 2015).

Una manera de lograr este objetivo ha sido adaptando los métodos de enseñanza tradicionales a las nuevas teorías pedagógicas, pero también aplicando estrategias digitales aprovechando las nuevas tecnologías que van surgiendo tales como el internet, la multimedia, y últimamente las redes sociales y los videojuegos. Estas estrategias digitales se refieren no sólo a las tecnologías, sino a las formas de utilización de dispositivos y software para enriquecer la enseńanza y el aprendizaje, ya sea dentro o fuera del aula.

Las estrategias digitales efectivas pueden ser utilizadas en el aprendizaje formal e informal; lo que las hace interesante es que trascienden las ideas convencionales y actividades de aprendizaje para crear algo que es nuevo y significativo, (Díaz \& Troyano, 2013).

El uso de la gamificación en el salón de clases como una herramienta para generar la motivación en los estudiantes y relacionar los conocimientos adquiridos en la escuela constituye un conjunto de estrategias que ayuda a crear un ambiente de armonía y trabajo en equipo, (Torres \& Lázaro, 2016).

La gamificación combina, tecnología, juego educativo y estrategia de refuerzo positivo para crear un entorno motivador y generar interés a través de juegos y concursos, (Rojas, 2017). Por su parte, Hamari \& Koivisto, (2013) afirma: La gamificación tiene como objetivo principal influir en el comportamiento de las personas durante la realización de la actividad del juego. Esta proposición fue comprobada como verdadera, después de que se aplicó en una clase estrategias de juego, que sirvieron para que los estudiantes se sientan tranquilos y hagan del aprendizaje algo divertido, (Hamari \& Koivisto, 2013).

Por otro lado, estas actividades permiten que los estudiantes se esfuercen y se sientan felices con las puntuaciones altas, y los que tienen notas algo bajas tienen la oportunidad de retroalimentar y mejorar sus promedios.

La aplicación de la gamificación mediante metáforas se ha convertido en un elemento clave en el proceso de enseñanza-aprendizaje, ya que se relacionan directamente con las diferentes áreas del aprendizaje y promueve en los estudiantes un espíritu crítico y reflexivo frente al contexto que los envuelve, aspecto primordial para la apropiación de conocimientos.

El uso de las plataformas virtuales de aprendizaje (Garibay \& Angelone, 2010; Morgado \& Schmidt, 2012), hoy en día se han convertido en un instrumento no solo en clases de educación a distancia, sino también en la educación presencial, pero muchas veces sólo se las usa de repositorios (Peña \& Tovar 2016), es entonces donde surgen iniciativas de combinarlas con estrategias lúdicas (Pereira \& Figueiredo, 2010; Díaz \& Troyano, 2013).

En la Tabla 1 se presentan algunas experiencias 
Metodología de Aprendizaje Basada en Metáforas Narrativas y Gamificación: Un caso de estudio en un Programa de Posgrado Semipresencial

de gamificación en contextos universitarios iberoamericanos que han dado resultados positivos. Se han excluido de forma intencional estudios llevados a cabo en otro idioma y contextos en donde la tecnología ya es una práctica común, esta revisión documental pretende encontrar similitudes en contextos cercanos al Ecuador.

\section{Tabla 1}

Experiencias de gamificación y metáforas en contextos universitarios

\begin{tabular}{llll}
\hline Año & \multicolumn{1}{c}{ Título } & País & Referencia \\
\hline 2013 & $\begin{array}{l}\text { La gamificación en la Universi- } \\
\text { dad para mejorar los resultados } \\
\text { académicos de los alumnos }\end{array}$ & & (Morales, \\
\hline 2014 & $\begin{array}{l}\text { Educación con Tecnologías: la } \\
\text { Gamificación Aplicada para el } \\
\text { Aprendizaje de la Programación }\end{array}$ & & \\
\hline 2015 & $\begin{array}{l}\text { Gamificación: Estrategia para } \\
\text { optimizar el proceso de apren- } \\
\text { dizaje y la adquisición de com- } \\
\text { petencias en contextos univer- } \\
\text { sitarios }\end{array}$ & (Willging et \\
al., 2014)
\end{tabular}

Fuente: Revisión Bibliográfica realizada por el autor (2018)

En el contexto de habla hispana se puede resumir que las aulas con estrategias de gamificación generan estudiantes motivados por aprender, mejora la retentiva, la capacidad de atención y de crítica reflexiva del aprendizaje; así como motiva y mejora la dinámica grupal y colaboración, finalmente, favorece las habilidades y actitudes positivas del aprendizaje significativo.

Si bien es cierto, se evidencian resultados alentadores, surge la curiosidad de probar qué resultados se encuentran en el contexto ecuatoriano, con la aplicación de una metodología que integra en una plataforma Moodle herramientas web $2.0 \mathrm{y}$ estrategias de metáforas narrativas y gamificación.

\section{Materiales Y Métodos}

\section{Participantes}

La muestra del estudio fue seleccionada de la Maestría en Educación, Innovación y Liderazgo Educativo de la Universidad Tecnológica Indoamérica, ubicada en la ciudad de Ambato, Ecuador. Se trabajó con $\mathrm{n}=62$ estudiantes. Siendo estos separados en dos grupos de 31 cada uno en el módulo de Infopedagogía Educativa. El promedio de edad de los estudiantes fue de 35,5 años. El 44,4\% correspondía al rango de 36 a 40 ańos, seguido del $18,5 \%$ en el rango de 41 a 45 ańos, el 14,8\% entre 26 a 30 ańos, el 11,1\% en el rango de 31 a 35 ańos y el resto en edades menores a 25 y mayores a 50 . Con relación al género el $90 \%$ correspondía al femenino. La formación del 75\% de los docentes se concentraba en Educación básica, seguido del $20 \%$ en educación secundaria y el $5 \%$ en educación superior.

\section{Instrumento}

Se utilizaron dos tipos de instrumentos para la recolección de datos, los foros de la plataforma Moodle y un cuestionario de Google Docs. El primero, de tipo cualitativo se utilizó para recabar información de las narrativas de los estudiantes en cada una de las actividades propuestas. Cada foro estaba diseńado para que participaran únicamente los estudiantes del grupo y de esta forma sistematizar sus narraciones, reflexiones y conclusiones. El procesamiento de esta información se realizó mediante el método de análisis de contenido, que tiene sus orígenes en la "teoría fundamentada" o 
“Grounded Theory” (Glaser \& Strauss 1967) y consiste en la generación o descubrimiento de categorías a partir de los datos recolectados y que constituye la base del análisis cualitativo. (Braun \& Clarke, 2006).

El segundo, de tipo cuantitativo estaba compuesto de 16 preguntas, 13 cerradas con escala Likert de 5 niveles ([1] Totalmente en desacuerdo [2] En desacuerdo [3] No estoy seguro [4] De acuerdo [5] Totalmente de acuerdo) y 3 abiertas. El cuestionario recoge datos demográficos y respuestas relacionadas al uso de la tecnología, las metáforas narrativas y el uso de la gamificación, con el fin de conocer niveles de aceptación o frustración sobre el uso de la metodología aplicada. Las preguntas del cuestionario se presentan en la Tabla 2

Tabla 2. Cuestionario para recoger datos demográficos y del caso de estudio

\begin{tabular}{|c|c|c|}
\hline No. & Pregunta & Opciones \\
\hline 1 & ¿En qué rango de edad se encuentra? & $\begin{array}{l}20-25,26-30,31- \\
35,36-40,41-45, \\
\text { mayor a } 45\end{array}$ \\
\hline 2 & ¿Cuál es su género? & $\begin{array}{l}\text { Femenino, Mas- } \\
\text { culino }\end{array}$ \\
\hline 3 & ¿Cuál es su formación académica? & Abierta \\
\hline 4 & ¿Qué actividad desempeña? & Abierta \\
\hline 5 & $\begin{array}{l}\text { ¿Cree usted que la tecnología utilizada } \\
\text { fomentó su participación en el proceso } \\
\text { de aprendizaje? }\end{array}$ & $\begin{array}{l}\text { Escala Likert de } 5 \\
\text { niveles }\end{array}$ \\
\hline 6 & $\begin{array}{l}\text { ¿Tuvo dificultades para manejar las tec- } \\
\text { nologías aplicadas en las actividades? }\end{array}$ & $\begin{array}{l}\text { Escala Likert de } 5 \\
\text { niveles }\end{array}$ \\
\hline 7 & $\begin{array}{l}\text { ¿Le pareció adecuada la metáfora utili- } \\
\text { zada en el módulo? ¿Cree que el uso de } \\
\text { la metáfora potenció la cooperación de } \\
\text { sus compañeros? }\end{array}$ & $\begin{array}{l}\text { Escala Likert de } 5 \\
\text { niveles }\end{array}$ \\
\hline 8 & $\begin{array}{l}\text { ¿Ha tenido alguna experiencia previa en } \\
\text { el uso de actividades lúdicas en el aula? }\end{array}$ & $\begin{array}{l}\text { Escala Likert de } 5 \\
\text { niveles }\end{array}$ \\
\hline 9 & $\begin{array}{l}\text { ¿En qué nivel cree usted adecuado el } \\
\text { uso de juegos en estudiantes de pos- } \\
\text { grado? }\end{array}$ & $\begin{array}{l}\text { Escala Likert de } 5 \\
\text { niveles }\end{array}$ \\
\hline 10 & $\begin{array}{l}\text { ¿Cree que la metodología aplicada en } \\
\text { el aula genera competencia? ¿Generó } \\
\text { frustración esta metodología de apren- } \\
\text { dizaje? }\end{array}$ & $\begin{array}{l}\text { Escala Likert de } 5 \\
\text { niveles }\end{array}$ \\
\hline 11 & $\begin{array}{l}\text { ¿Generó motivación esta metodología } \\
\text { de aprendizaje? }\end{array}$ & $\begin{array}{l}\text { Escala Likert de } 5 \\
\text { niveles }\end{array}$ \\
\hline 12 & $\begin{array}{l}\text { ¿Qué tiempo promedio ha dedicado a } \\
\text { las actividades de la plataforma diaria- } \\
\text { mente? }\end{array}$ & $\begin{array}{l}\text { Escala Likert de } 5 \\
\text { niveles }\end{array}$ \\
\hline 13 & $\begin{array}{l}\text { ¿Se cumplió el objetivo del módulo con } \\
\text { la propuesta metodológica? }\end{array}$ & $\begin{array}{l}1 \text { hora, } 2 \text { horas, } 3 \\
\text { horas, } 4 \text { horas, } 5 \\
\text { horas }\end{array}$ \\
\hline
\end{tabular}

\begin{tabular}{lll}
\hline 14 & $\begin{array}{l}\text { ¿Le gustaría recibir otros módulos con } \\
\text { esta metodología? }\end{array}$ & $\begin{array}{l}\text { Escala Likert de } 5 \\
\text { niveles }\end{array}$ \\
\hline 15 & $\begin{array}{l}\text { ¿Cree usted que la tecnología utilizada } \\
\text { fomentó su participación en el proceso } \\
\text { de aprendizaje? }\end{array}$ & Si, No, ¿por qué? \\
\hline 16 & $\begin{array}{l}\text { ¿Qué otras consideraciones haría usted } \\
\text { sobre esta experiencia? }\end{array}$ & Abierta \\
\hline
\end{tabular}

Fuente: Elaboración propia

\section{Tipo y diseńo}

De acuerdo con la pregunta de investigación y a los objetivos planteados, la investigación es de tipo aplicada, orientada a la solución práctica a problemas. En otras palabras, el investigador busca resolver un problema conocido y encontrar respuestas a preguntas específicas (León \& Montero, 2003). El diseño de la investigación tiene un enfoque exploratorio-descriptivo. Exploratorio, ya que, aborda una temática poco estudiada, relacionada a la percepción de estudiantes adultos con procesos de enseñanza-aprendizaje basada en juegos. Justamente, en este contexto se desarrolla la contribución de la presente investigación, ya que las estrategias de metáforas narrativas y gamificación se han usado en contextos universitarios, pero con estudiantes jóvenes, quienes tienen habilidades en el manejo de la tecnología. Descriptivo, ya que, a través de la observación de los fenómenos en su ambiente natural, la aplicación de los instrumentos y el análisis de los datos se caracteriza a la muestra y se describen tendencias de la práctica de gamificación con el apoyo de la tecnología (Hernández, Fernández \& Baptista, 2010, p. 149).

\section{Procedimiento}

Se trabajó con dos grupos de 31 estudiantes en el módulo de Infopedagogía Educativa, el cual tenía por objeto la introducción de la tecnología en el aula y cómo se integra con la pedagogía. Con cada grupo se trabajó cinco semanas, con una sesión presencial de ocho horas cada semana.

La metodología de aprendizaje utilizada en este estudio estuvo compuesta de tres fases: planeamiento, desarrollo y evaluación. En la primera, se realizó el diseño de la estrategia pedagógica de 
El siguiente paso, fue propiciar el trabajo colaborativo, para ello los estudiantes conformaron un equipo para trabajar en las horas presenciales y virtuales. Para lograr la participación de todos los integrantes, cada equipo debió elegir un líder, quien fue el encargado de motivar a todo su equipo a través de mensajes en un foro creado para cada equipo. En el escenario de la Academia de Magia Hogwarts, los estudiantes se registraron en una de las casas de confraternidad, tales como, Gryffindor, Hufflepuff, Ravenclaw, Slytherin u otras que nacieron de la creatividad del docente.

En la plataforma virtual de aprendizaje se crearon aulas metafóricas que contenían recursos visuales y multimediales, que propiciaron la participación de todos los integrantes del grupo. En un foro, por ejemplo, los estudiantes emitieron una votación y elección del líder, quien fue el encargado de motivar a todos los compañeros para ganar los puntos en los diferentes desafíos.

El rol del docente fue el de supervisor y quien tuvo el control total y brindó retroalimentación a cada equipo. De esta manera el docente pudo monitorear por medio de la plataforma el aporte de cada estudiante. Por ejemplo, en el caso de estudio de Hogwarts actuó de Basilisco, en el caso de Silicon Valley actuó de Ángel Inversor, en el caso de Inteligencia Artificial actuó de Dr. Know o en el caso de Emprendimiento actuó de Superintendente en Economía Social y Solidaria.

El diseño de las estrategias de aprendizaje basadas en gamificación combina recursos teóricos y prácticos estructurados en foros, consultas, wikis, blogs, chat, glosario, encuestas y tareas de la plataforma Moodle. Se combinan también con diapositivas interactivas desarrolladas con Microsoft PowerPoint + Macros programadas en Visual Basic; así como herramientas de la web 2.0, tales como Voki (Crea personajes animados text-tospeech), YouTube (videos educativos), Dotsub (Videos didácticos tipo plain text) y aplicaciones de dispositivos móviles para simular Clickers (sencillo sistema de respuesta personal remota), para evaluación como Kahoot, Quizizz Plickers o convertir una demostración de láminas simples en una ilustración que cobra vida por medio de la realidad aumentada mediante la ayuda de dispositivos móviles y aplicaciones gratuitas, tales como QUIVERVISION, SPACE 4D, ANIMAL 4D, HUMANOID 4D. En estos casos se diseñó una metáfora de la varita mágica que representó a un teléfono inteligente y la metáfora del cristal mágico que representó a una tableta. También se introdujeron recursos tecnológicos físicos, como sensores, tarjetas electrónicas o robots educativos. En el caso de estudio se utilizó Microsoft Kinect para la metáfora del "Espejo mágico" con la que se estudiaron las interfaces naturales de usuario y Kiteracy (Kit de lectoescritura basado con letras y objetos tangibles) con las que se estudiaron las interfaces tangibles (Jadán-Guerrero \& Ramos-Galarza, 2016).

Con todos estos recursos el docente diseñó estrategias de aprendizaje con un sinnúmero de retos y desafíos, lo cual permitió al estudiante recoger pistas para encontrar las llaves que abrieron nuevas puertas de conocimiento hasta llegar a la meta. Con esta metodología se motivó a los estudiantes a trabajar en equipo y a revisar detenidamente el material de apoyo para encontrar las posibles pistas, que fueron discutidas en el foro con el resto del equipo. Cada sesión constituyó un nivel y en cada nivel se obtuvo puntos por la realización de las diferentes actividades. En la última sesión cada equipo construyó un ensayo con la experiencia del módulo y cada estudiante completó una encuesta con 16 preguntas.

\section{Confidencialidad}

Es importante indicar que se pidió el consentimiento informado para la participación voluntaria de los estudiantes y se guardó la confidencialidad de los datos recogidos en la plataforma virtual. Es decir, se actuó bajo protocolos de seguridad adecuados para el resguardo de la información durante el procesamiento de información y presentación de resultados en el presente documento. 


\section{Resultados}

El presente estudio además del uso de las plataformas virtuales y herramientas web 2.0 introduce la metáfora narrativa y la gamificación en programas de Posgrado de modalidad semipresencial. Esta propuesta, es el resultado de experiencias similares que los autores han venido utilizando en varios cursos de programas de posgrado de diferentes Instituciones de Educación Superior, entre los que se pueden destacar: En la Maestría en Educación, Innovación y Liderazgo Educativo, se aplicó la metáfora de la Academia de Magia Hogwarts en el módulo de Infopedagogía y la metáfora del Abogado del Diablo en el módulo de investigación Científica. En la Maestría de Economía Social y Solidaria se aplicó una metáfora basada en el desarrollo de una comunidad ecuatoriana llamada "Salinas", en la Maestría en Gerencia Informática la metáfora de Silicon Valley, en la Maestría de TIC para la Gestión y Práctica Docente se utilizó la metáfora de las Olimpiadas, en la Maestría de Bases de Datos Distribuidas se aplicó la metáfora del Dr. Know basada en la película Inteligencia Artificial. También esta metodología se ha aplicado en cursos de Educación Continua para la enseñanza a docentes universitarios de escritura de artículos científicos; así como de estadística inferencial. Para ejemplificar la aplicación de la propuesta metodológica se describe un caso de estudio en el módulo de Infopedagogía Educativa.

\section{Caso de estudio: La Academia de Magia Hogwarts}

La metáfora narrativa de la Academia de Magia Hogwarts se aplicó en el módulo de Infopedagogía Educativa, como parte de la Maestría en Educación, Innovación y Liderazgo Educativo de la Universidad Tecnológica Indoamárica. El estudio se llevó a cabo con dos grupos de 31 estudiantes cada uno, todos los estudiantes del curso son docentes de educación primaria, secundaria y universitaria. El curso centró la atención en la identificación de tecnologías que podrían incorporarse en el aula y las estrategias pedagógicas adecuadas. Una manera de lograr esta introducción de forma práctica y vivencial fue a través de la literatura, como lo es el libro "Harry Potter y la piedra filosofal", obra que está presente en la realidad de muchos niños y adolescentes, a través del cine. Esta metáfora en un contexto de la enseñanza de lenguaje y comunicación ha dado resultados positivos (Ramos \& Duarte, 2006), ya que ha despertado el interés de los estudiantes. Tomando esta idea, se consideró en el presente estudio que puede ser un instrumento adecuado para introducir la "magia" de la tecnología en la realidad de los estudiantes de posgrado.

La experiencia comenzó con la presentación del sílabo del módulo y posteriormente la del video que describe el escenario y los retos que los estudiantes debían afrontar. El docente hizo una breve narración de la historia e interactuó con los estudiantes para identificar la trama de la metáfora y del nivel de conocimientos de las herramientas tecnológicas en el aula. Seguidamente, se solicitó a cada estudiante que ingrese a la Cafetería Virtual para realizar una narración de las experiencias con la tecnología en el ámbito personal y laboral. En la Figura 2 se visualiza el escenario de la primera sesión.

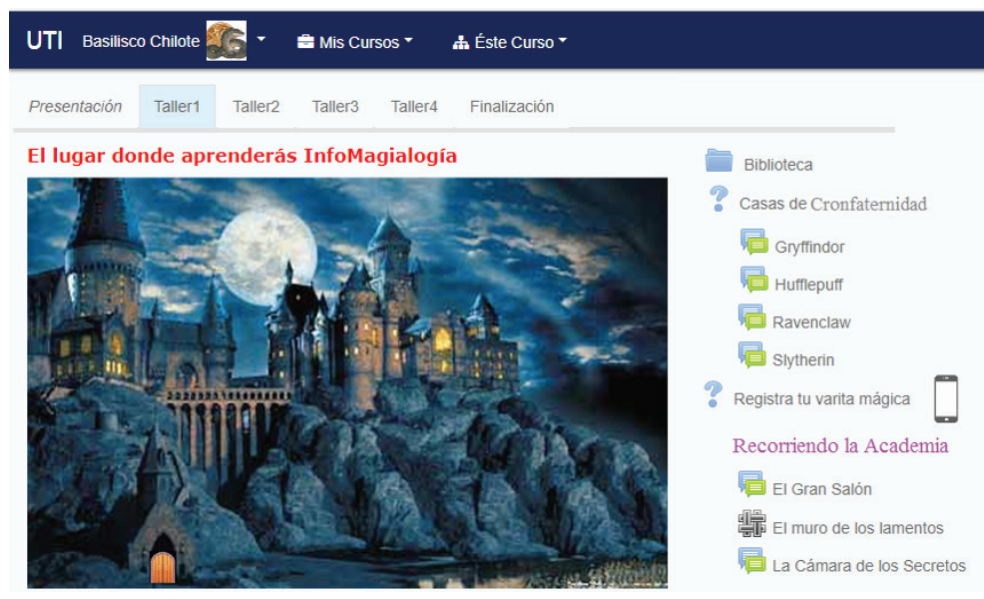

Figura 2. Escenario de la primera sesión del curso de Infopedagogía Educativa

La Biblioteca, tiene libros y artículos científicos digitales relacionados a la Infopedagogía. Además, tiene una lista de enlaces a repositorios de documentos técnicos y científicos, como se muestra en la Figura 3. 
Metodología de Aprendizaje Basada en Metáforas Narrativas y Gamificación: Un caso de estudio en un Programa de Posgrado Semipresencial

Las puertas tenían enlaces a libros y artículos científicos, en los cuales debían buscar una palabra clave para abrir la siguiente puerta, las pistas eran dadas por Basilisco a través de un mensaje grabado en Voki. El objetivo era que el estudiante hiciera una lectura profunda del documento y si era necesario vuelva a leerlo hasta encontrar la llave. El docente usando el rol de Basilisco era quien monitoreaba todos los mensajes que se escribían en los foros diseñados para cada confraternidad. Algunas actividades se realizaban en el aula y otras cada estudiante desde su hogar, en los dos casos el docente retroalimentaba y motivaba a los estudiantes.

En las sesiones presenciales los estudiantes pusieron en práctica los conceptos estudiados en los videos, por ejemplo, el enlace El Muro de los Lamentos es una wiki de Moodle que el docente diseñó para recoger información de los estudiantes sobre la problemática del uso de las TIC en sus instituciones educativas.

En la segunda sesión se realizaron actividades para incorporar en el aula otros dispositivos tecnológicos, como los teléfonos inteligentes en calidad de clickers y otros dispositivos emergentes para actividades lúdicas, como se puede ver en la Figura 6.

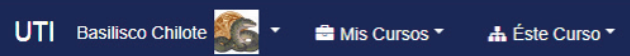

Presentación Taller1 Taller2 Taller3 Taller4 Finalización

Introducción a movimientos de la varita mágica
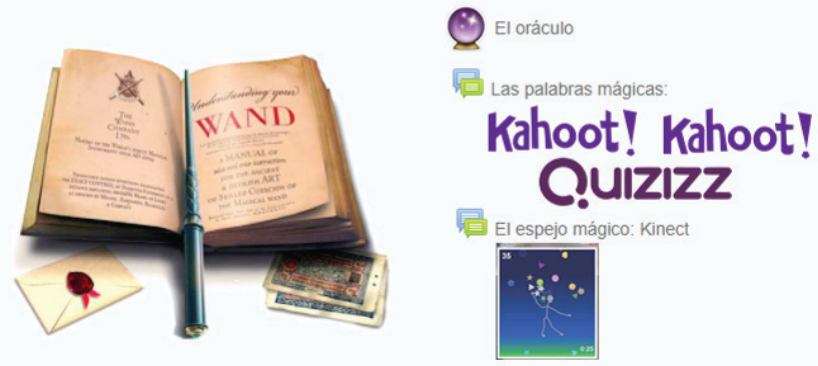

Figura 6. Escenario de la segunda sesión, con TIC de evaluación

La actividad El oráculo contenía una base de datos de preguntas relacionadas a los temas vistos en la sesión anterior y lecturas como retos en los días de trabajo autónomo. En la actividad Las palabras mágicas se utilizaron dos aplicaciones móviles Kahoot! Y Quizizz para desarrollar una actividad de evaluación lúdica, cada estudiante descargó las aplicaciones en su teléfono móvil y el docente tomaba un cuestionario para proyectarlo en la pantalla, mediante un código generado por la aplicación cada estudiante o el grupo se conectaba al juego para responder las preguntas presentadas.

En esta actividad, se pudo observar una activa participación de los estudiantes, pero también se evidenció que se generó un espacio de competencia. En consonancia con el objetivo de introducir novedad y emociones, es loable resaltar, que en jornadas largas permite romper la monotonía.

Otra forma en la que se rompió la monotonía fue la introducción de la actividad física, mediante El espejo mágico: Kinect, en la que se utilizó un sensor Microsoft Kinect y el juego Shape Game, con el fin de que los estudiantes no se centren únicamente en actividades frente al computador. Esta actividad utiliza una Interfaz Natural de Usuario, es decir reconoce los movimientos corporales de una persona, la cual se ve reflejada tal cual en un espejo en la pantalla y mediante comandos de voz y movimientos de su cuerpo evita que caigan al suelo objetos que caen del cielo.

Esta actividad despertó interés de los estudiantes, el $90 \%$ de ellos desconocía el dispositivo, lo cual generó curiosidad y a su vez se generó un espacio de motivación. El objetivo fue introducir el tema de tecnologías emergentes que ayuden a fortalecer la interacción en el aula y reflexionar sobre las estrategias didácticas que deben acompañar a estos instrumentos de andamiaje tecnológico.

En este contexto se introdujo a Makey Makey, una tarjeta electrónica similar al mando de una videoconsola que simula las teclas de flechas o ratón, para enviar órdenes al computador e interactuar con videojuegos o software de instrumentos musicales. Se introdujo también Kiteracy, un kit de lectoescritura para nińos con necesidades educativas especiales, compuesto de un oso de peluche conectado a un computador, con la habilidad de identificar letras tangibles de plástico u objetos para fortalecer la conciencia fonológica. Este kit fue producto de un proyecto de investigación desarrollado en la Universidad Tecnológica Indoamérica y era la oportunidad para articular investigación con la docencia (Jadán-Guerrero \& Ramos-Galarza, 2016). 
En la tercera sesión se diseñó un escenario en donde los estudiantes crearon sus propios recursos educativos interactivos, para ello se utilizó PowerPoint y macros programados con Visual Basic, el escenario se puede ver en la Figura 7.

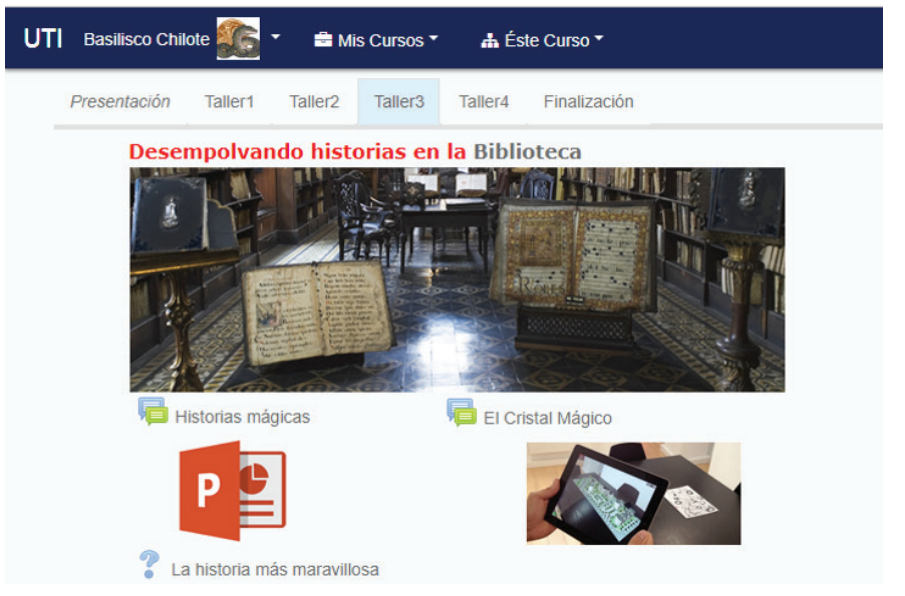

Figura 7. Escenario de la tercera sesión, creación de recursos educativos

El objetivo en esta sección fue la de crear una historia con preguntas y respuestas. En la actividad La historia más maravillosa se utilizó la herramienta consulta de Moodle en donde todos votaron por la la historia más creativa, cada estudiante dio su voto desde la plataforma y se visualizó las estadísticas de las historias presentadas. Algo interesante de destacar es que esta actividad generó un ambiente de competencia, ya que los estudiantes eran quienes calificaban a sus compañeros.

Finalmente, en la actividad El Cristal mágico se introdujo el uso de tabletas con la aplicación de realidad virtual QuiverVision. Para ello se entregó a cada estudiante una hoja con un dibujo y se pidió colorear, hasta ese momento no sabían para qué eran las hojas, y la asociaban con la historia realizada anteriormente. El reto fue usar el cristal mágico para encontrar pistas que Basilisco les había dejado. Fue evidente la sorpresa de los estudiantes cuando vieron que una simple hoja tome vida en la tableta.

En la cuarta sesión se preparó un escenario de un viaje imaginario a las aulas del futuro, y descubrir cómo aprenden los estudiantes del siglo XXI, para ello se utilizó la metáfora del Expreso de Hagwarts, como se muestra en la Figura 8.

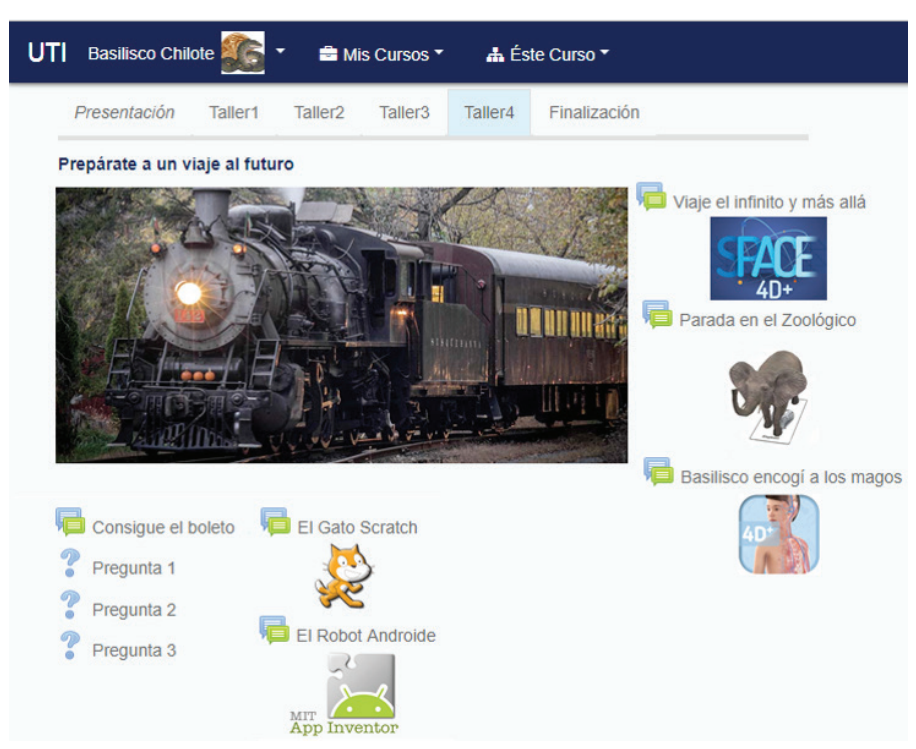

Figura 8. Escenario de la cuarta sesión de un viaje imaginario al futuro

El primer paso fue adquirir el tiquete de abordar, para ello los estudiantes debían contestar tres preguntas, si las respuestas era las correctas podían subir al expreso. La travesía en el expreso hacía varias paradas, la primera era la del Gato Scratch, el reto era aprender el lenguaje del gato para que realice varias acciones, entre ellas, caminar, bailar o jugar con una pelota. El objetivo se enfocó en el lenguaje de programación por bloques que provee la aplicación y su potencial uso como una tecnología educativa para la innovación en la práctica docente, (Cruz, Rivadeneira, Villanova, Torres \& Varas, 2015).

La siguiente parada fue la del Robot Androide, en la cual los estudiantes con el lenguaje aprendido programaban su varita mágica en MIT App Inventor para leer códigos QR. Para ello se solicitó a cada estudiante un cuento físico para convertirlo en un cuento interactivo. Los estudiantes aprendieron a generar códigos $\mathrm{QR}$ asociados a un archivo de formato MP3 o un enlace de video. Estos códigos fueron recortados y pegados en las hojas del cuento. Mediante la App desarollada e instalada en cada dispositivo móvil, el estudiante podía identificar dibujos del cuento o bien narrar la historia con su voz. El objetivo, fue crear recursos educativos para niños que empiezan el proceso de lectura con el fin de desarrollar habilidades de lenguaje y nuevo vocabulario.

Las siguentes paradas tenían como propósito co- 
nocer más aplicaciones de realidad virtual, tales como, SPACE 4D, que permite explorar el sistema solar, ANIMAL 4D, que muestra animales en su entorno natural y HUMANOID 4D que permite explorar el cuerpo humano en sus diferentes vistas, sistema óseo, sistema sanguíneo y otros órganos. Todas estas aplicaciones usan tarjetas de papel, que tienen marcas que generan la realidad virtual en tabletas o dispositivos móviles. La estrategia del docente fue entregar a cada estudiante una tarjeta y siguiendo la metáfora del viaje, indicarles que son las entradas al planetario, al zoológico y a un proceso de miniaturización para explorar un museo del cuerpo humano.

Finalmente, en la quinta sesión cada casa de confraternidad presentó un ensayo utilizando herramientas de ofimática on-line como Google Docs o Microsoft Office 360. El ensayo se presentó en formato de artículo científico y cada casa debía realizar una narración de la experiencia del módulo.

El objetivo de esta actividad fue introducir aspectos de colaboración en línea mediante la edición de un documento en forma colaborativa. También, cada estudiante completó un formulario de Google Docs con preguntas relacionadas a la aplicación de las metáforas y la gamificación. Por último, cada grupo presentó una exposición de las estrategias aprendidas por medio de la herramienta PowToon. En la Figura 9 se puede ver el diseño del escenario.

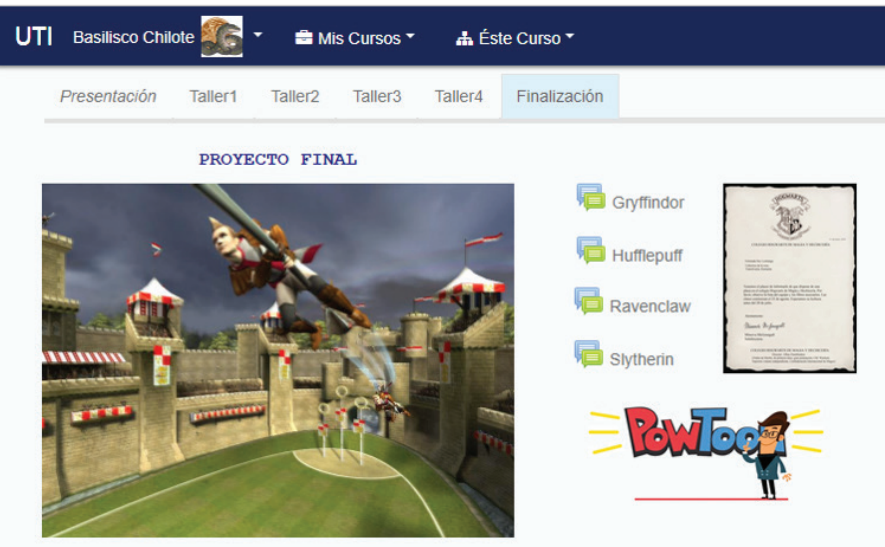

Figura 9. Escenario de la quinta sesión de cierre y presentación final

En cada una de las sesiones se fueron recogiendo las narraciones de los participantes en los foros di- señados para cada actividad. Mediante el método de análisis de contenido se buscó la interpretación del texto para identificar aspectos positivos o negativos de la metodología aplicada; así como también conocer la apreciación de las tecnologías introducidas en cada actividad. Tomando en cuenta el gran volumen de información generada por los 62 participantes en 25 foros, se utilizó la herramienta TagCrowd para generar categorías basadas en la frecuencia de término (Ver Figura 10).

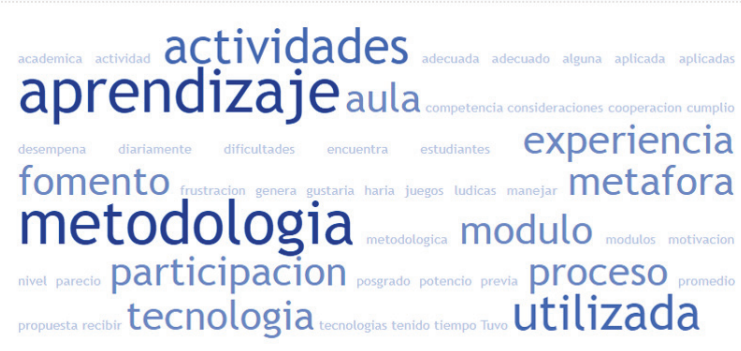

Figura 10. Categorías generadas con la herramienta TagCrowd

De forma general se puede concluir que la metodología de aprendizaje aplicada en los dos grupos tuvo una aceptación por parte de los estudiantes. Los participantes describían su experiencia en términos positivos, recalcando que no habian tenido experiencias similares. Las categorías más marcadas se centraban en motivación, participación, colaboración, interacción, interés, nuevo, entre otras, que se detallan en la sección de discución.

Con el fin de confirmar y precisar los resultados cuantitativos encontrados, se diseñó una encuesta, basada en las categorías identificadas, en la cual se obtuvieron los resultados que se muestran en la Tabla 3. La primera columna corresponde al número de pregunta, ya que se eliminaron las referentes a datos demográficos, la segunda columna corresponde al texto de la pregunta y las siguientes cinco columnas corresponden a los items de la escala Likert. Los valores que se muestran en estas columnas corresponde al porcentaje de cada item. 
Tabla 3: Resultados de la encuesta a los estudiantes

\begin{tabular}{|c|c|c|c|c|c|c|}
\hline No. & Pregunta & $\begin{array}{l}{[1]} \\
\%\end{array}$ & $\begin{array}{l}{[2]} \\
\%\end{array}$ & $\begin{array}{l}{[3]} \\
\%\end{array}$ & $\begin{array}{c}{[4]} \\
\%\end{array}$ & $\begin{array}{c}{[5]} \\
\%\end{array}$ \\
\hline P5 & $\begin{array}{l}\text { ¿Cree usted que la tecno- } \\
\text { logía utilizada fomentó su } \\
\text { participación en el proceso } \\
\text { de aprendizaje? }\end{array}$ & 0 & 0 & 3,7 & 11,1 & 85,2 \\
\hline P6 & $\begin{array}{l}\text { ¿Tuvo dificultades para ma- } \\
\text { nejar las tecnologías aplica- } \\
\text { das en las actividades? }\end{array}$ & 25,9 & 14,8 & 55,6 & 3,7 & 0 \\
\hline P7 & $\begin{array}{l}\text { ¿Le pareció adecuada la } \\
\text { metáfora utilizada en el mó- } \\
\text { dulo? }\end{array}$ & 0 & 0 & 0 & 25,9 & 74,1 \\
\hline P8 & $\begin{array}{l}\text { ¿Cree que el uso de la metá- } \\
\text { fora potenció la cooperación } \\
\text { de sus compañeros? }\end{array}$ & 0 & 0 & 0 & 29,6 & 70,4 \\
\hline P9 & $\begin{array}{l}\text { ¿Ha tenido alguna experien- } \\
\text { cia previa en el uso de acti- } \\
\text { vidades lúdicas en el aula? }\end{array}$ & 0 & 0 & 30,8 & 50,0 & 19,2 \\
\hline P10 & $\begin{array}{l}\text { ¿En qué nivel cree usted } \\
\text { adecuado el uso de juegos } \\
\text { en estudiantes de posgrado? }\end{array}$ & 0 & 0 & 3,7 & 33,3 & 63,0 \\
\hline & $\begin{array}{l}\text { ¿Cree que la metodología } \\
\text { aplicada en el aula genera } \\
\text { competencia? }\end{array}$ & 0 & 3,8 & 11,1 & 40,7 & 44,4 \\
\hline P11 & $\begin{array}{l}\text { ¿Generó frustración esta } \\
\text { metodología de aprendiza- } \\
\text { je? }\end{array}$ & 29,6 & 40,7 & 25,9 & 3,8 & 0 \\
\hline P12 & $\begin{array}{l}\text { ¿Generó motivación esta } \\
\text { metodología de aprendiza- } \\
\text { je? }\end{array}$ & 0 & 0 & 7,4 & 22,2 & 70,4 \\
\hline P13 & $\begin{array}{l}\text { ¿Qué tiempo promedio ha } \\
\text { dedicado a las actividades } \\
\text { de la plataforma diariamen- } \\
\text { te? }\end{array}$ & 51,9 & 22,2 & 18,5 & 3,7 & 3,7 \\
\hline P14 & $\begin{array}{l}\text { ¿Se cumplió el objetivo del } \\
\text { módulo con la propuesta } \\
\text { metodológica? }\end{array}$ & 0 & 0 & 0 & 33,3 & 66,7 \\
\hline P15 & $\begin{array}{l}\text { ¿Le gustaría recibir otros } \\
\text { módulos con esta metodo- } \\
\text { logía? }\end{array}$ & 0 & 0 & 0 & 29,6 & 70,4 \\
\hline P16 & $\begin{array}{l}\text { ¿Cree usted que la tecno- } \\
\text { logía utilizada fomentó su } \\
\text { participación en el proceso } \\
\text { de aprendizaje? }\end{array}$ & 0 & 0 & 0 & 25,9 & 74,1 \\
\hline
\end{tabular}

Escala Likert: [1] Totalmente en desacuerdo [2] En desacuerdo [3] No estoy seguro [4] De acuerdo [5] Totalmente de acuerdo

A continuación se presentan las figuras 11, 12, 13, 14 y 15 en donde se expone el análisis estadístico descriptivo basado en el porcentaje de respuestas de los participantes al instrumento aplicado. Estas estadísticas corresponden a las preguntas clave que dieron respuesta a nuestra pregunta de investigación.
¿Cree usted que la tecnología utilizada fomentó su participación en el proceso de aprendizaje?
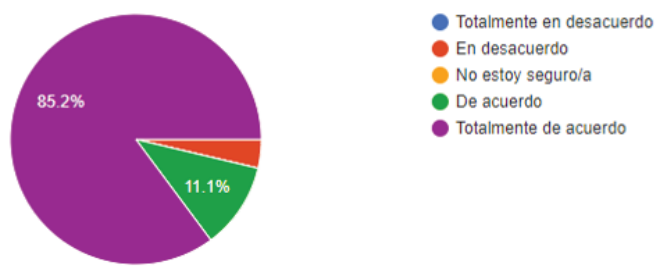

Figura 11. Pregunta P5 sobre el uso de tecnología en el aula ¿Cree que el uso de la metáfora potenció la cooperación de sus
compañeros?

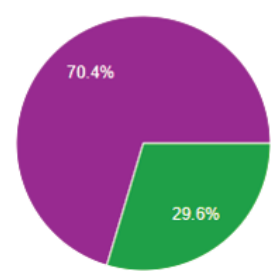

- Totalmente en desacuerdo

- En desacuerdo

No estoy seguro/a

- De acuerdo

- Totalmente de acuerdo

Figura 12. Pregunta P8 sobre el uso de la metáfora

¿En qué nivel cree usted adecuado el uso de juegos en estudiantes de posgrado?
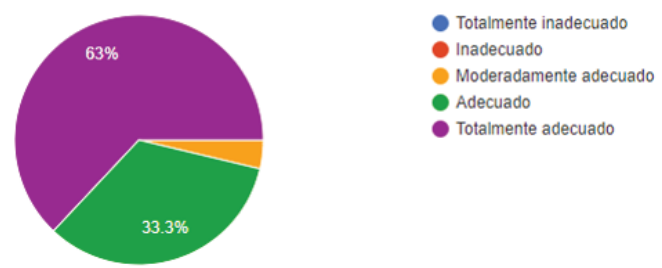

Figura 13. Pregunta P10 sobre el uso de la gamificación en el aula

\section{¿Generó frustración esta metodología de aprendizaje?}
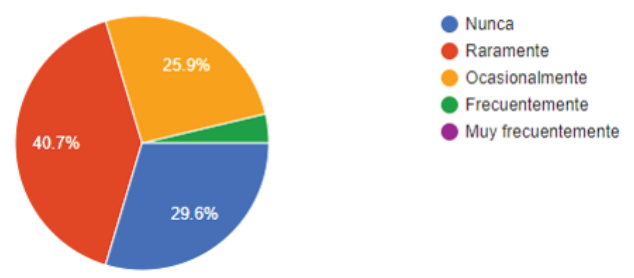

Figura 14. Pregunta P11 sobre la frustración en la metodología de aprendizaje 
¿Generó motivación esta metodología de aprendizaje?

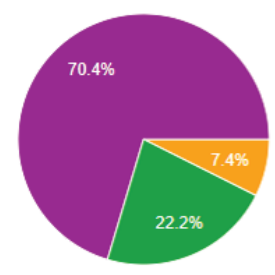

Nunca

Raramente

- Frecuentemente

- Muy frecuentemente

Figura 15. Pregunta P12 sobre el uso de la metodología de aprendizaje

De acuerdo a la información presentada y las propias narraciones de los estudiantes se evidenció que fue una estrategia muy novedosa y diverti$\mathrm{da}$, se pudo trabajar colaborativamente entre los participantes a través de preguntas de foros, consultas, cuestionarios y herramientas web 2.0. Esta metodología además permitió que se fomente la resolución de problemas, el aprendizaje, la motivación y las emociones. Estas últimas constituyen un factor determinante en el aprendizaje significativo, ya que influyen directamente en el desarrollo cognitivo a través de una huella duradera, positiva o negativa (Cruz, 2017).

Por otro lado, en el aspecto negativo en la Figura 14, que muestra estadísticas de la pregunta 11 sobre la frustración se puede observar que existió un porcentaje bajo. Este hecho evidencia que las metáforas narrativas y las estrategias de gamificación puede ser aplicable a estudiantes adultos logrando significativos porcentajes de interracción, motivación e involucramiento. Justamente la contribución de este estudio está en primer lugar en el diseño de una metodología que integra tecnología, metáforas narrativas y estrategias de gamificación, en segundo lugar que es aplicable a participantes adultos, a diferencia de otros estudios aplicables en contextos universitarios, pero con estudiantes más jóvenes (Área, San Nicolás \& Fariña, 2010).

\section{Discusión y Conclusiones}

La observación por parte de los autores en comparación con módulos dictados en modalidad magistral y sin apoyo de la gamificación, evidenció que se generó mayor expectativa e interacción por parte de los estudiantes. Incluso trabajando cada uno desde su casa en modalidad on-line. Durante la implementación tecnológica, se observó la motivación de los estudiantes porque leyeron y revisaron los documentos una y otra vez hasta descifrar los acertijos. Esto ayudaba a que el estudiante complemente su estudio teórico sin ser forzado. Tanto en las clases presenciales como en las no presenciales los estudiantes participaron activamente. Los que más conocían de la parte práctica, guiaban a los que menos experiencia tenían.

El monitoreo en línea y los registros dejados por la plataforma permitieron corroborar esta aseveración. El tiempo que el estudiante permanecía conectado y activo en la plataforma superaba la hora diaria estipulada. También los comentarios dejados por los propios estudiantes, manifestaron que aprendieron de una manera divertida y apoyándose entre ellos, por ejemplo, una estudiante manifiestó lo siguiente:

“...en el módulo con el uso de metáforas es una de las mejores aplicaciones que he utilizado últimamente dentro de la plataforma, la academia de Hogwarts con la estrategia de hacernos sentir que estamos en una dimensión mágica como es las sagas de Harry Potter, que, ¿a quién no le llama la atención? pues todos sabemos hemos leído o simplemente visto alguna película de este personaje, ya que, más que todo la lectura de cada libro que se está introduciendo en las escuelas para fomentar el hábito y cultura de la lectura porque llama la atención conocer estas mágicas historias y que nos hace sentirnos seres diferentes, o parte de estos personajes, y que el uso de aplicaciones nos ayuda a concentrarnos y entusiasmarnos a practicar con la tecnología con la dirección o control de Basilisco que es el jefe mago que también nos enseña, ayuda y evalúa en cada proceso o taller con retos que hemos cumplido con gran énfasis y desempeño, y mucho interés lo cual han causado nuevamente el gusto y entusiasmo hacia la tecnología, ya que hay herramientas más fáciles de utilizar como fue el lenguaje de programación SCRATCH donde diseñamos nuestro propio juego con rapidez y desenvoltura, que en comparación a los lenguajes antes utilizados para programar y 
realizar un juegos o sistema, pues era tan extenso, molesto, y complicado para poder llegar al objetivo, e incluso tedioso porque sólo se trataba de líneas de código fuente..."

Se evidenció trabajo colaborativo pero también competitivo. La desventaja de la competición es que, el fracaso o éxito depende en gran medida de los resultados de otros equipos, y en muchas ocasiones va de la mano de comparaciones. Este hecho generó inconformidad en los dos grupos estudiados, especialmente cuando se pedía a los estudiantes usar los clikers para votar o puntuar por un trabajo de otra confraternidad. Frente a esta situación el docente trató de promover el espíritu coopetitivo; es decir una competencia sana, pues competir significa competición con uno mismo unido a la cooperación con los demás.

Las estrategias basadas en metáforas y gamificación han permitido cambiar el aprendizaje pasivo a una forma más dinámica y entretenida para afrontar largas sesiones de trabajo. Así como la participación espontánea en foros y cuestionarios. La reflexión, el análisis crítico y las narrativas fueron más naturales. En los diferentes escenarios, el docente actuó como catalizador para lograr reflexión por los estudiantes.

El uso de las plataformas virtuales de aprendizaje facilitaron la integración de las estrategias lúdicas con los recursos propios de la plataforma Moodle $y$ herramientas web 2.0. Si bien se requiere de un arduo trabajo previo, para la generación de los recursos, una vez implementado, al docente le permiten hacer un uso más eficiente del tiempo en el salón de clases y fuera de él.

El uso de la tecnología y todas sus herramientas permite a los integrantes del quehacer educativo desarrollarse de una manera más atractiva, permite la interacción directa entre los educandos y educadores y sobre todo permite alcanzar los objetivos didácticos, priorizando la comunicación y la participación de todos.

Los estudiantes lograron con gran facilidad adaptarse a la tecnología y en sus narraciones coinciden en que los docentes debemos apropiarnos de estas tecnologías para hacer de las clases interesantes e innovadoras, por ejemplo, una narrativa expresada por una estudiante :

“...el poder trabajar en el módulo de Infopedagogía y aprender a utilizar la tecnología ha permitido que seamos docentes con otro pensamiento, buscar diferentes estrategias de enseñanza con la utilización de aplicaciones que están al alcance de nuestras manos con tan solo dar un clic, los docentes en la actualidad tienen un gran reto ante los estudiantes, ya que ellos se adaptan fácilmente al momento de utilizar un computador, celular, iphone, y otros aparatos electrónicos. Con la aplicación de la gamificación en el aula permite dar un cambio en la educación creando un entorno seguro de enseñanza permitiendo que exista por el estudiante la conexión de emoción y formación, favoreciendo de esta manera la colaboración, esfuerzo y desarrollo del conocimiento..."

Indiscutiblemente, la utilización de herramientas tecnológicas en la actualidad nos ayuda hacer el aprendizaje más divertido e innovador siendo este un pilar fundamental para la enseñanza aprendizaje, ya que esto tiende a descubrir nuevas estrategias metodológicas para la adquisición de nuevos conocimientos. A continuación otra narrativa descrita por un estudiante.

“...en este módulo las experiencias fueron fantásticas, entretenidas e innovadoras, los mismos que fructificarán los conocimientos y que a su vez serán aplicados en la labor educativa, porque la educación va enmarcada en educar para la vida, propone nuevos modelos y procesos de enseñanza que hace accesible a diferentes campos mediante la tecnología como canales de comunicación y facilita la interacción social grupal..."

Mediante el análisis del discurso de las diferentes narrativas de los estudiantes, se concluye que al aplicar la metodología propuesta se pudo obtener como resultado, que los estudiantes expresaran aspectos positivos en el uso de esta metodología.

De acuerdo a los resultados de la encuesta, se confirma con el 85,2\% de los estudiantes encontraron a las tecnologías como un elemento motivador, un $74,1 \%$ encontró apropiada el uso de metáforas, un $63 \%$ aceptó que la gamificación puede 
Metodología de Aprendizaje Basada en Metáforas Narrativas y Gamificación: Un caso de estudio en un Programa de Posgrado Semipresencial

ser adecuada en estudiantes adultos y un 70,4\% encontró motivación en la metodología aplicada.

Por otro lado, en el aspecto negativo se puede indicar que el 55,6\% de los estudiantes tuvo ocasionalmente dificultades para manejar la tecnología, el $44,4 \%$ indica que a pesar de existir actividades de colaboración, si se genera competencia grupal. Finalmente, el $3.7 \%$ pone en evidencia que se sintió frustrado y desconcertado con las actividades, sin embargo, el contacto con el grupo le ayudó a superar. Es importante que estos resultados corresponden a la población estudiada y no se puede generalizar, de todas maneras en experiencias anteriores se pudo observar una tendencia a los beneficios que ofrece esta metodología.

Partiendo sobre la base de que una metáfora es una representación de la realidad llevada a un mundo imaginario, hipotético, o de ficción, constituye un componente fundamental de la cognición que posibilita la integración de los conceptos nuevos en los campos de conocimiento ya existentes.

Las aulas metafóricas constituyen una variación del campus virtual con la incorporación de recursos de hipertexto y multimedia que favorecen la interacción de los estudiantes con los materiales didácticos y las actividades. La metáfora convierte al aula en un ambiente que introduce al estudiante en la temática de estudio, generando una relación más estrecha y propician la empatía y la comprensión. (Requena, 2017).

En este sentido, se ha podido evidenciar en el módulo de Infopedagogía que los alumnos generaron ideas y desarrollaron su pensamiento metafórico partiendo desde sus experiencias. En algunos casos fueron puestos en práctica inmediatamente con sus alumnos de educación primaria o secundaria.

Una conclusión que se puede sacar de este estudio, es que no solamente la aplicación de la tecnología favorecerá al aprendizaje significativo, sino que la verdadera evolución se localiza en las formas de implementar y evaluar las acciones educativas a través de procesos pedagógicos. Esta conclusión es corroborada por Navarro (2010), quien considera que la tecnología es una herramienta didáctica siempre y cuando su implementación persiga un objetivo educativo.
La investigación y desarrollo tecnológico han llevado a la humanidad a un nivel de progreso en conocimientos, habilidades y destrezas en diferentes áreas, entre ellas la educación. Pero quizá aún faltan encontrar estrategias de aplicación de tecnología en el aula. Hoy estamos en un momento de inflexión, y está en nuestra manos dar un giro a la educación, mediante procesos de innovación para enfrentar los desafíos del siglo 21.

Si bien es cierto la innovación en el aula a través de estrategias lúdicas de aprendizaje genera motivación e interacción, también es importante destacar que se generaron espacios de competencias, en los que prevalecía el premio antes que el aprendizaje. Un factor relevante en la aplicación de estas estrategias es el esfuerzo y conocimiento que requiere el docente para diseñar y crear los diferentes recursos. La incorporación de las TIC y la integración con estrategias de gamificación supone mayor trabajo y dedicación para el docente (Morales, Trujillo \& Raso, 2015).

\section{REFERENCIAS BIBLIOGRÁFICAS}

Alarcón, P., Díaz, C., Tagle, T., Ramos, L. \& Quintana, M. (2014). Metáforas para profesor y estudiante de pedagogía, en un grupo de estudiantes de pedagogía chilenos. Revista Electrónica. Actualidades Investigativas en Educación, 4(2), 1-31. Recuperado de https://revistas.ucr.ac.cr/index.php/ aie/article/viewFile/14829/14111

Álvarez, J., Belmonte, L., \& Román, I. (2016). Metáforas y abstracciones en asignaturas de Ingeniería y Economía como vía para reducir el fracaso en la docencia universitaria. Congreso Universitario Internacional sobre la Comunicación en la Profesión y en la Universidad de hoy: Contenidos, investigación, innovación y docencia (CUICIID), Caracas, Venezuela.

Alvites-Huamaní, C. (2017) Herramientas TIC en el aprendizaje en el área de Matemática: Caso Escuela PopUp, Piura-Perú. Hamut'ay, 4 (1), 18-30. https://doi.org/10.21503/ hamu.v4i1.1393

Área, M., San Nicolás, M. \& Fariña, E., (2010). Buenas prácticas de aulas virtuales en la docencia universitaria semipresencial, TESI, 11 (3), 7-31. Recuperado de https:// gredos.usal.es/jspui/bitstream/10366/72859/1/BUENAS_ PRACTICAS_DE_AULAS_VIRTUALES_EN_.pdf

Avello, R., Rodríguez, R. \& Dueñas, J. (2016). Una experiencia con Moodle y herramientas web 2.0 en el Postgrado. Revista Universidad y Sociedad, 8(4), 58-64. Recuperado de http://scielo.sld.cu/scielo.php?script=sci_arttext\&pi- 


\section{$\mathrm{d}=S 2218-36202016000400007 \& \operatorname{lng}=e s \& t \operatorname{lng}=e s$}

Bermúdez, I. (2007). Debian GNU/Linux. Para El Usuario Final, Morrisville: Editorial Lulu.

Braun, V., \& Clarke, V. (2006). Using thematic analysis in psychology. Qualitative research in psychology, 3(2), 77-10. https://doi.org/10.1191/1478088706qp063oa

Camacho, I., \& Fuentes, J. (2013). Entornos Virtuales de Aprendizaje Metafórico. Revista digital de información educativa, 6-20.

Capted, D. (2011). Metáforas visuales en los mundos virtuales. El Caso de NANEC 2010/2011. Revista de Innovación Educativa, 6, 38-45.

Cruz, D., Rivadeneira, S., Villanova, G., Torres, M. \& Varas, C. (2015). Tecnología educativa como herramienta para la innovación en la práctica docente. XVII Workshop de Investigadores en Ciencias de la Computación. Recuperado de http://sedici.unlp.edu.ar/bitstream/handle/10915/46425/ Documento_completo.pdf?sequence $=1$

Cruz, S. (2017). El aprendizaje significativo y las emociones: una revisión del constructo original desde el enfoque de la neurociencia cognitiva. XIV Congreso Nacional de Investigación Educativa.

Díaz, J. \& Troyano, Y. (2013). El potencial de la gamificación aplicado al ámbito educativo. En III Jornadas de Innovación Docente. Innovación Educativa: respuesta en tiempos de incertidumbre Sevilla, España: Universidad de Sevilla. Facultad de Ciencias de la Educación. Recuperado de https://idus.us.es/xmlui/bitstream/handle/11441/59067/ EL\%20POTENCIAL\%20DE\%20LA\%20GAMIFICACION\%20APLICADO\%20AL\%20AMBITO\%20EDUCATIVO.pdf?sequence $=1$ \&isAllowed $=y$

Duran, N. (2015), Herramientas tecnológicas aplicadas a la educación superior para docentes innovadores a través de un ambiente virtual de aprendizaje metafórico, Virtual Educa, Guadalajara, México. Recuperado de http:// www.virtualeduca.red/documentos/23/Herramientas $\% 20$ tecnol\%C3\%B3gicas\%20aplicadas\%20a\%20la\%20educaci $\% \mathrm{C} 3 \% \mathrm{~B} 3 \mathrm{n} \% 20$ superior $\% 20$ para $\% 20$ docentes $\% 20$ innovadores $\% 20 \mathrm{a} \% 20$ trav\%C3\%A9s\%20de\%20un\%20ambiente\%20virtual\%20de\%20aprendizaje\%20metaf\%C3\%B3rico.pdf

Garibay, M. \& Angelone, S., (2010). A b-learning experience in higher education. Information Systems and Technologies (CISTI), 2010 5th Iberian Conference, Santiago de Compostela, España.

Glaser, B., \& Strauss, A. (1967). The discovery of Grounded Theory: Strategies for Qualitative inquiry. Chicago: Aldin. Estados Unidos.

Guarneros-Reyes, E., Espinoza-Zepeda, A, Silva, A. \& Sánchez-Sordo, J. (2016). Diseño de un curso autogestivo modular en línea de metodología de la investigación para universitarios, México. Hamut'ay, 3 (2), 7-24. https://doi. org/10.21503/hamu.v3i2.1305
Guerrero, D., Peña, D., Peña, A. \& Serna, E. (2017). Nuevas tendencias en educación, juegos serios con tecnología móvil en Windows 10 Mobile. Espiral, Revista de Docencia e Investigación, 7(1), 61-72. https://doi.org/10.15332/erdi. v7i1.1778

Oliva, H. (2016). La gamificación como estrategia metodológica en el contexto educativo universitario, Realidad y Reflexión, 44, 29-47. https://doi.org/10.5377/ryr.v44ii0.3563

Hamari, J. \& Koivisto, J. (2013). Social motivations to use gamification: an empirical study of gamifying excercice. En Proceedings of the 21st European Conference on Information Systems, Utretch, Netherlands.

Hernández, R., Fernández, C. \& Baptista, P. (2010). Metodología de la Investigación. México:McGrawHill.

Jadán-Guerrero, J. \& Ramos-Galarza, C. (2016). El rol de la Psicología en el Desarrollo de Tecnología Educativa. Revista CienciAmérica, 5 (1) 100-103. Recuperado de http:// www.cienciamerica.us/openjournal/index.php/uti/article/ view/51/39

Lazarte, A. (1995). La Psicología y el estadístico intuitivo, Boletín del Instituto Riva Agüero, 22, 147-162. Recuperado de http://revistas.pucp.edu.pe/index.php/boletinira/ article/view/9705/10116

León, O. \& Montero, I. (2003). Métodos de Investigación en Psicología y Educación. Madrid: McGraw-Hill.

Llorens-Largo, F. (2017). Tendencias en innovación educativa y su implantación en la UPM. III Jornada Gamificación: Insert coin to play again. Cátedra Santander-UA de Transformación Digital de la Universidad de Alicante. Recuperado de https://rua.ua.es/dspace/bitstream/10045/70732/1/ Gamificacion-Tendencias-en-innovacion-educativa-UPM-2017.pdf

Llorens-Largo, F., Gallego-Durán, F. J., Villagrá-Arnedo, C. J., Compañ-Rosique, P., Satorre-Cuerda, R. \& Molina-Carmona, R. (2016) Gamification of the Learning Process: Lessons Learned, IEEE Revista Iberoamericana de Tecnologías del Aprendizaje, 11 (4), 227-234.

Lojan, M. (2017). Patrones en gamificación y juegos serios, aplicados a la educación. Tesis de la Maestría en Informática Educativa, Universidad Técnica de Ambato. Recuperado de http://repositorio.uta.edu.ec/bitstream/123456789/26793/1/Tesis_Mar\%C3\%ADa_ del\%20Cisne_Loj\%C3\%A1n.pdf

Martí-Parreño, J., Queiro-Ameijeiras, C., Méndez-Ibáńez, E. \& Giménez-Fita, E. (2015). El uso de la gamificación en la educación Superior: el caso de Trade Ruler. XII Jornadas Internacionales de Innovación Universitaria Educar para transformar: Aprendizaje experiencial. Recuperado de http://abacus.universidadeuropea.es/bitstream/handle/11268/4314/jiiu_2015_11.pdf?sequence=2\&isAllowe$\mathrm{d}=\mathrm{y}$

Mera-Paz, J. (2016). Gamificación una estrategia de fortalecimiento en el aprendizaje de la ingeniería de sistemas, experiencia significativa en la Universidad Cooperativa de Colombia sede Popayán, Revista Científica de la Universidad 
Metodología de Aprendizaje Basada en Metáforas Narrativas y Gamificación: Un caso de estudio en un Programa de Posgrado Semipresencial

Distrital Francisco José de Caldas, 3 (26) 3-11. Recuperado de https://revistas.udistrital.edu.co/ojs/index.php/revcie/article/view/11085/11927

Minović, M., García-Peñalvo, F. \& Kearney, N. (2016). Gamification Ecosystems in Engineering Education. International Journal of Engineering Education, 32(1B), 308309.

Morales, J. (2013). La gamificación en la universidad para mejorar los resultados académicos de los alumnos. Quinto Congreso Virtual Iberoamericano de Calidad en Educación Virtual y a Distancia.

Morales, M., Trujillo, J. \& Raso, F. (2015). Percepciones acerca de la integración de las TIC en el proceso de enseñanza-aprendizaje de la universidad. Revista de Medios y Educación, 46, 103-117. https://doi.org/10.12795/pixelbit.2015.i46.07

Morgado, E. \& Schmidt, R. (2012). Increasing Moodle resources through Cloud Computing. Information Systems and Technologies (CISTI), 7th Iberian Conference,1(4), 20-23.

Pastor-Pina, H., Satorre-Cuerda, R., Molina-Carmona, R., Gallego-Durán, F. J. \& Llorens-Largo F. (2015). Can Moodle be used for structural gamification?. International Association of Technology, Education and Development.

Peña, J. \& Tovar, N. (2016). Webinario: herramienta de integración en clases virtuales, Venezuela. Hamut'ay, 3 (2), 25-41. https://doi.org/10.21503/hamu.v3i2.1308

Pereira, I. \& Figueiredo, A. (2010). Promoting motivation and participation in higher education: A b-learning experience, Frontiers in Education Conference.

Quesada Mora, V. A., Gallego-Durán, F. J., Molina-Carmona, R. \& Llorens-Largo, F. (2017). Subliminal Learning. What Do Games Teach Us?. International Conference on Learning and Collaboration Technologies.

Rama, C. (2014). Las innovaciones digitales en educación y la irrupción de una pedagogía informática. Hamut'ay, 1 (1), 52-64. https://doi.org/10.21503/hamu.v1i1.573

Ramos, R. \& Duarte, D. (2006). El best seller en las clases de español: enriquecimiento léxico mediante la lectura de las aventuras del mago Harry Potter. Actas del XIV Seminario de Dificultades Específicas de la Enseñanza del Español a Lusohablantes.

Requena, I. (2017). Enfoques metafóricos e iconográficos: aplicación en la personalización de espacios virtuales de aprendizaje. Revista Digital La Pasión del Saber, 7 (13).

Rodríguez, F. \& Santiago, R. (2015). Gamificación: Cómo motivar a tu alumnado y mejorar el clima en el aula. Editorial Océano.

Rojas, M. (2012). Las metáforas de aprendizaje como hilo conductor en la construcción de aulas virtuales una experiencia práctica. Valencia-Carabobo: Universidad José Antonio Páez. proceso de enseñanza y aprendizaje en el uso de la tecnología a los estudiantes del colegio Fray José María Arévalo del Municipio de la Playa de Belén.

Sánchez, F. (2015). Gamificación. Education in the Knowledge Society (EKS), 16 (2), 13-15. https://doi.org/10.14201/ eks20151621315

Torres, A. \& Lázaro, D. (2016). El proceso de gamificación en el aula: Las matemáticas en educación infantil. GRIN Verlag.

Torres-Toukoumidis, A., Romero-Rodríguez, L. \& Pérez-Rodríguez, M. (2018). Ludificación y sus posibilidades en el entorno de blended learning: revisión documental. RIED. Revista Iberoamericana de Educación a Distancia, 21(1), 95. https://doi.org/10.5944/ried.21.1.18792

Vargas-Enríquez, J., García-Mundo, L., Genero, M., \& Piattini, M. (2015). Análisis de uso de la Gamificación en la Enseńanza de la Informática. Actas de las XXI Jornadas de la Enseńanza Universitaria de la Informática, Andorra La Vella.

Villalustre, L. \& Del Moral, E. (2015). Gamificación: Estrategia para optimizar el proceso de aprendizaje y la adquisición de competencias en contextos universitarios, Digital Education Review, 27, 13-31.

Willging, P., Astudillo, G., Bast, S, Castro, L. \& Distel, J. (2014). Educación con Tecnologías: la Gamificación Aplicada para el Aprendizaje de la Programación, XIX Workshop de Investigadores en Ciencias de la Computación, Buenos Aires, 1169-1173

Rojas, L. (2017). Implementación de la Gamificación en el 